\title{
Production and characterization of Brassica napus-Raphanus sativus monosomic addition lines mediated by the synthetic amphidiploid "Raphanobrassica"
}

\author{
Michiko Akaba',2), Yukio Kaneko*1), Youichi Ito" ${ }^{1)}$, Yoshimi Nakata'), Sang Woo Bang1) \\ and Yasuo Matsuzawa ${ }^{1)}$ \\ 1) Laboratory of Plant Breeding, Faculty of Agriculture, Utsunomiya University, 350 Minemachi, Utsunomiya, Tochigi 321-8505, Japan \\ 2) United Graduate School of Agriculture, Tokyo University of Agriculture and Technology, 3-5-8, Saiwai, Fuchu, Tokyo 183-8509, \\ Japan
}

In order to breed Brassica napus-Raphanus sativus monosomic addition lines (MALs), hybridizations between two synthetic amphidiploid (RRAA and RRCC) and B. napus (AACC) were performed. Two allooctoploids (RRAAAACC and AACCRRCC) were produced from each $\mathrm{F}_{1}$ hybrid by chromosome doubling. From successive backcrosses to $B$. napus, MAL plants were first obtained in $\mathrm{BC}_{2}$ generation and the $R$. sativus-derived chromosome was identified by genomic in situ hybridization (GISH). The nine chromosomes of R-genome in the MAL plants were clearly classified by each chromosome-specific RAPD markers. As a result, alloplasmic (radish cytoplasm) B. napus - R. sativus MAL having 8 types (a-i, except for h-type) and autoplasmic (rape cytoplasm) MAL with complete 9 types $(\mathrm{a}-\mathrm{i})$ were obtained in $\mathrm{BC}_{3}$ and $\mathrm{BC}_{4}$ generations. These alloplasmic and autoplasmic MAL plants were showed differences in their morphological, physiological and cytogenetical characters. From the survey of favorable traits, it was suggested that the a-type had fertility restoring gene(s) for male sterility in alloplasmic line and the g-type had a gene controlling white color petal. These two MALs are useful materials for exploring agronomic traits located on each chromosome of radish and for promoting the introgression of promising radish gene(s) to B. napus.

Key Words: Raphanus sativus, Brassica napus, Raphanobrassica, monosomic addition lines (MALs), random amplified polymorphic DNA (RAPD), genomic in situ hybridization (GISH).

\section{Introduction}

Although radish (Raphanus sativus L. $2 \mathrm{n}=18$, RR genome) is one of the most important vegetables in East Asia (Kaneko et al. 2007), rape (Brassica napus L. $2 \mathrm{n}=38$, AACC genome), which includes winter and spring oilseed, fodder and vegetables rape forms, is today the most widely cultivated crop species in the crucifer family (Brassicaceae) (Snowdon et al. 2007). Radish possesses agronomically useful traits such as resistances to beet cyst nematode (Heterodera schachtii) (Lelivelt and Krens 1992, Peterka et al. 2004), clubroot (Plasmodiophora brassicae) (Ashizawa et al. 1980) and white rust (Albugo candida) (Kolte et al. 1991) and cytoplasmic male sterility (CMS) (Ogura 1968, Ikegaya 1986a, 1986b). Other Brassicaceae crops often lack these traits, and a large number of rape cultivars are susceptible to beet cyst nematode (Peterka et al. 2004) and clubroot (Ashizawa et al. 1980). Therefore, radish can be used as a nuclear and/or cytoplasm donor plant for the modification of rape.

A number of intergeneric hybridizations between rape and radish have been performed in order to introduce agro-

Communicated by T. Terachi

Received August 25, 2008. Accepted February 19, 2009.

*Corresponding author (e-mail: kaneko@cc.utsunomiya-u.ac.jp) nomically useful traits of radish to rape, but only a few hybrid plants were obtained due to their poor crossability (Dolstra 1982). To overcome these poor crossability, several breeding methods have been performed: ovary culture (Luo et al. 1989), ovule culture (Dolstra 1982), sequential culture (Lelivelt et al. 1993), flower-culture (Metz et al. 1995), in vitro organ culture (Luo et al. 2000), and protoplast fusion (Pelletier et al. 1983, Sakai and Imamura 1990, Lelivelt and Krens 1992, Sakai et al. 1996, Wang et al. 2006). Furthermore, it has been also difficult to produce backcross progenies in this cross-combination (Dolstra 1982). On the other hand, it is relatively easy to obtain $\mathrm{F}_{1}$ hybrids and backcross progenies by the hybridization between Brassicoraphanus (B. rapa $\times$ R. sativus, $2 \mathrm{n}=38$, AARR genome) and $B$. napus, when Brassicoraphanus was used as a bridging plant (Dolstra 1982, Paulmann and Röbbelen 1988).

The addition lines of a single alien chromosome to the full complement of the recipient species are called monosomic addition lines (MALs), and morphological and physiological features of MALs are affected by an alien chromosome (Khush 1973). Since O'Mara (1940) had first produced MAL in wheat, it has been successfully bred in many crops. In Brassicaceae with a number of important agricultural crops, several MAL series have been successfully bred through interspecific and intergeneric hybridizations to 
express their phenotypic characteristics (Kaneko et al. 1987, 2001, Quiros et al. 1987, 1988, Jahier et al. 1989, Struss et al. 1991, Chen et al. 1992, Srinivasan et al. 1998, Bang et al. 2002, Peterka et al. 2004). These MALs have been also analyzed to locate the agronomic traits and gene(s) on the added chromosome (Zhu et al. 1993, Chévre et al. 1996, 1997, Kaneko et al. 1996, Chen et al. 1997, Peterka et al. 2004, Bang et al. 2009). However, only a few studies report the production of alloplasmic and autoplasmic MALs with the same nuclear background (Budahn et al. 2008, Bang et al. 2009).

Recently, Budahn et al. (2008) reported the production of alloplasmic and autoplasmic $B$. napus - R. sativus MALs with radish and rape cytoplasms, respectively. However, no detailed genetic analyses have been performed to characterize each type of these two MALs.

In this study, we tried to breed alloplasmic and autoplasmic B. napus $-R$. sativus MALs $(2 \mathrm{n}=39)$ by crossing between $B$. napus and two synthetic amphidiploids "Raphanobrassica": RA-89 (R. sativus $\times$ B. rapa, $2 \mathrm{n}=38$, RRAA, Matsuzawa et al. 2000) and Rb-63 (R. sativus $\times$ B. oleracea, $2 \mathrm{n}=36$, RRCC, Matsuzawa et al. 1985), as the bridging plants to donate the radish chromosome and cytoplasm into B. napus $(2 \mathrm{n}=38$, AACC). Each $R$. sativus chromosome in MALs was identified by random amplified polymorphic DNA (RAPD) analysis and cytogenetical observations including genomic in situ hybridization (GISH). Morphological and physiological features of the added chromosomes were also studied to characterize and maintain these two MALs.

\section{Materials and Methods}

\section{Plant materials}

Two synthetic amphidiploids, Raphanobrassica 'RA-89' $(2 n=38$, RRAA) and ' $R b-63$ ' $(2 n=36, R R C C)$ are stocks of the Laboratory of Plant Breeding, Utsunomiya University, Japan. Raphanobrassica 'RA-89' was developed by hybridization of R. sativus L. cv. 'Risou' $(2 \mathrm{n}=18, \mathrm{RR})$ and B. rapa L. ssp. Japonica cv. 'Kyo-mizuna' ( $2 \mathrm{n}=20$, AA) (Matsuzawa et al. 2000). Raphanobrassica 'Rb-63' was developed from crossing between R. sativus L. cv. 'Shogoin' $(2 \mathrm{n}=18, \mathrm{RR})$ and B. oleracea L. var. acephala cv. 'Murasaki-habotan' $(2 \mathrm{n}=18, \mathrm{CC})$ (Matsuzawa et al. 1985). Brassica napus strain ' $\mathrm{N}-350$ ' used for the recurrent parent is an accession of Cruciferae genetic stocks from the Laboratory of Plant Breeding, Tohoku University, Japan. Two R. sativus L. cv. 'Shogoin' and 'Risou' are stocks of the Laboratory of Plant Breeding, Utsunomiya University, Japan.

\section{Production of monosomic addition lines (MALs)}

The schematic diagram for breeding of alloplasmic and autoplasmic MALs was shown in Fig. 1. Two Raphanobrassica and B. napus strain ' $\mathrm{N}-350$ ' were grown in pots in a greenhouse. The hybridizations between two Raphanobrassica and B. napus strain ' $\mathrm{N}-350$ ' were per- formed using the conventional crossing method. Flower buds were emasculated one day before anthesis, immediately pollinated with fresh pollen and then bagged for about a week. To induce octoploidy, $0.2 \%$ colchicine solution was applied with small cotton plugs to the apical meristem of $\mathrm{F}_{1}$ seedlings. To obtain the backcross progenies, $\mathrm{F}_{1}$ plants were successively backcrossed with $B$. napus strain ' $\mathrm{N}-350$ ' using the conventional crossing method. Embryo culture was also made for embryo rescue in some cases, according to the method of Bang et al. (1996). The somatic chromosome numbers of $F_{1}$ plants and their backcross progenies were counted using the Feulgen stain squash method followed by $1 \%$ acetocarmine staining.

For alloplasmic line, $\mathrm{BC}_{2}$ plants were produced from 2 $\mathrm{BC}_{1}$ plants with $2 \mathrm{n}=47$ and 52 , and $\mathrm{BC}_{3}$ plants were obtained from $5 \mathrm{BC}_{2}$ plants with $2 \mathrm{n}=39$ to 43 by backcrossing to $B$. napus strain ' $\mathrm{N}-350$ '. Autoplasmic $\mathrm{BC}_{2}$ and $\mathrm{BC}_{3}$ plants were produced from $3 \mathrm{BC}_{1}$ plants with $2 \mathrm{n}=47$ and 48 and 5 $\mathrm{BC}_{2}$ plants with $2 \mathrm{n}=40$ to 42 by backcrossing to $B$. napus strain 'N-350', respectively.

To classify the plants into nine types of MALs corresponding to R-genome, all the plants with $2 \mathrm{n}=39$ were first analyzed by the RAPD specific markers for each chromosome of R-genome in the $\mathrm{BC}_{3}$ generation, and were successfully maintained as distinctive MALs in the $\mathrm{BC}_{4}$ or $\mathrm{BC}_{5}$ generation through successive backcrosses to $B$. napus strain 'N-350'.

\section{RAPD analysis}

Polyacrylamide gel electrophoresis was employed according to Kaneko et al. (2001) with some modifications.

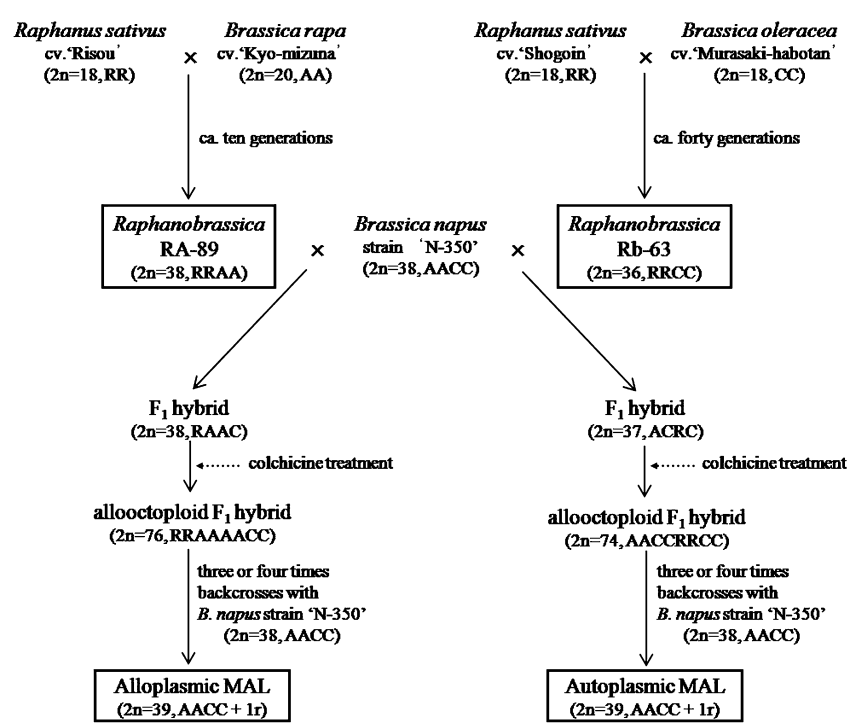

Fig. 1. The schematic diagram for breeding of alloplasmic and autoplasmic MALs. Raphanobrassica 'RA-89' was developed by hybridization of $R$. sativus $\mathrm{L}$. cv. 'Risou' $(2 \mathrm{n}=18, \mathrm{RR})$ and $B$. rapa $\mathrm{L}$. ssp. Japonica cv. 'Kyo-mizuna' $(2 \mathrm{n}=20$, AA) (Matsuzawa et al. 2000). Raphanobrassica 'Rb-63' was developed from crossing between R. sativus L. cv. 'Shogoin' $(2 \mathrm{n}=18, \mathrm{RR})$ and B. oleracea $\mathrm{L}$. var. acephala cv. 'Murasaki-habotan' ( $2 \mathrm{n}=18, \mathrm{CC})$ (Matsuzawa et al. 1985). 
Total DNA was isolated from young leaves using CTAB method. Reaction mixture $(10 \mu \mathrm{l})$ contained $4 \mathrm{ng}$ of genomic DNA, $0.2 \mu \mathrm{M}$ of primer, $0.5 \mathrm{mM}$ dNTPs (TOYOBO, Osaka, Japan), $1 \times$ reaction buffer (Promega, Madison, WI, USA), and 1 unit of Taq polymerase (Promega) were pipetted into $0.2 \mathrm{ml}$ tubes, and PCR was performed using Program Temp Control system PC-320 (ASTEC Co., Fukuoka, Japan). After an initial 5-min denaturation step at $94^{\circ} \mathrm{C}$, fragments of DNA were amplified for 45 cycles $\left(94^{\circ} \mathrm{C}\right.$ for $30 \mathrm{sec}, 35^{\circ} \mathrm{C}$ for $30 \mathrm{sec}, 72^{\circ} \mathrm{C}$ for $1 \mathrm{~min}$ ) with the extension step of the last cycle extended to $10 \mathrm{~min}$. The amplified products were mixed with loading dye and loaded on a $0.5 \%$ polyacrylamide gel prepared in $1 \times$ TBE buffer. After electrophoresis, the gel was stained with ethidium bromide and viewed with a UV illuminator.

The primers which yield R-genome specific markers were selected from the 400 12-mer sequences (Common A to D, BEX, Tokyo, Japan). The consistent markers observed in both Raphanobrassica and R. sativus but not observed in B. napus strain ' $\mathrm{N}-350$ ' were assigned to R-genome specific RAPD markers. Using these RAPD markers, those specific to each radish chromosome of nine MALs were identified in the total of $14 \mathrm{BC}_{2}$ plants with $2 \mathrm{n}=39$ to 43 in alloplasmic line. For autoplasmic line, more than 4 markers corresponding to each radish chromosome were selected from each MAL of alloplasmic line and used for identification of added radish chromosomes. These procedures were repeated twice.

\section{Chromosome identification by GISH}

Genomic in situ hybridization was performed with somatic cells of the $2 \mathrm{n}=39$ plants, $R$. sativus, B. napus and Raphanobrassica. Chromosome preparation was performed using enzymatic maceration/air-drying method (Fukui 1996) with some modifications. Briefly, excised roots were pretreated with 8 -hydroxyquinoline ( $2 \mathrm{mM}$ aqueous solution) at room temperature for $2 \mathrm{~h}$, thereafter at $4^{\circ} \mathrm{C}$ for $2 \mathrm{~h}$, and fixed in $3: 1$ ethanol: acetic acid for $24 \mathrm{~h}$ before being stored in $70 \%$ ethanol at $-20^{\circ} \mathrm{C}$. Fixed root tips were washed two times in $1 \times$ enzyme buffer $(10 \mathrm{~min}$ each $)$ and digested enzymatically for $90 \mathrm{~min}$ at $37^{\circ} \mathrm{C}$ in a mixture comprising $2 \%$ cellulose 'Onozuka R-10' (Serva, Heidelberg, Germany) and $20 \%$ pectolyase Y-23 (SIGMA, St. Louis, MO, USA) in $1 \times$ enzyme buffer. After a short rinse in $1 \times$ enzyme buffer, the root tips were squashed in a drop of $3: 1$ ethanol: acetic acid. The coverslip then were removed by freezing, and the preparations were dehydrated by air drying.

Labeling of the DNA probes and genomic in situ hybridization were carried out according to the methods described in Schwarzacher et al. (1994) with some modifications. In short, genomic DNA isolated from R. sativus cv. 'Risou' was labeled with Tetramethyl-rhodamine-5-dUTP (Roche, Mannheim, Germany) by nick translation following the protocol provided by the manufacture (Roche).

Chromosome preparations were pre-treated with DNasefree RNase $(100 \mu \mathrm{g} / \mathrm{ml})$ in $2 \times \mathrm{SSC}$ for $1 \mathrm{~h}$ at $37^{\circ} \mathrm{C}$, washed in $2 \times \mathrm{SSC}$ for $15 \mathrm{~min}$, post-fixed with formaldehyde (4\% aque- ous solution) for $10 \mathrm{~min}$, washed in $2 \times \mathrm{SSC}$ for $15 \mathrm{~min}$, and dehydrated in an ethanol dilution series before being airdried. The hybridization mixture consisted of $50 \%$ deionized formamide, $10 \%$ dextran sulphate, $2 \times \mathrm{SSC}$ and $0.25 \%$ SDS, and probe DNA was added to a concentration of $20 \mathrm{ng}$ per slide. As a blocking DNA, genomic DNA isolated from $B$. napus strain ' $\mathrm{N}-350$ ' was also mixed to a concentration of $400 \mathrm{ng}$ per slide. The hybridization mixture was denatured for $10 \mathrm{~min}$ at $70^{\circ} \mathrm{C}$, the slides were denatured together for 5 min at $80^{\circ} \mathrm{C}$ and the probes hybridized for $16 \mathrm{~h}$ in a humid chamber at $37^{\circ} \mathrm{C}$. Slides were washed stringently with $2 \times$ $\mathrm{SSC}$ for $10 \mathrm{~min}$ at $42^{\circ} \mathrm{C}$ and then with $0.2 \times \mathrm{SSC}$ for $5 \mathrm{~min}$ at $42^{\circ} \mathrm{C}$. Finally, preparations were mounted in Vectashield (Vector Laboratories, Burlingame, CA, USA) containing 2.5 $\mu \mathrm{g} / \mathrm{ml}$ of 4',6-diamidino-2-phenylindole (DAPI; Serva).

Images were acquired with a computer-assisted cooled charge CCD camera (AxioCam MRm, Zeiss, Jena, Germany) attached to Zeiss Axio vert 200M epifluorescence microscope with the system software (Axio Vision Release 4.5, Zeiss), and retouched using Adobe Photoshop 7.0.

Characteristics of alloplasmic and autoplasmic MALs and transmission rate of the added alien chromosome

To characterize each type of alloplasmic and autoplasmic MALs, morphological, physiological, and cytogenetical characteristics were examined in the $\mathrm{BC}_{4}$ and/or $\mathrm{BC}_{5}$ generations. Germination rate was calculated with approx. 50 seeds of each type 1 week after sowing. Measurement of petal length and verification of flower malformation were made with ten flowers in full bloom. Pod length was measured with twenty pods 4 weeks after crossing. Meiotic chromosome configuration was examined at metaphase I (MI) in pollen mother cells (PMCs) using the $1 \%$ acetic orcein smear method. The ratio of pollen tetrads was assessed by observing about 100 cells stained with $1 \%$ acetic orcein. Pollen fertility was verified by examining 500 pollen grains from three flowers in full bloom using $1 \%$ acetocarmine staining method. Seed fertility was examined by calculating the ratio of seeds setting per pod developed from ca. 50 flowers when the MAL plants were backcrossed with rape.

Using RAPD markers specific to each chromosome, transmission of the added chromosome in each type of MALs through female gametes was rated with ca. 50 individuals from each type in the $\mathrm{BC}_{4}$ and/or $\mathrm{BC}_{5}$ generations.

\section{Results}

Development and identification of alloplasmic and autoplasmic MALs

In the hybridizations between two Raphanobrassica and rape (B. napus, strain ' $\mathrm{N}-350$ '), 27 and $19 \mathrm{~F}_{1}$ hybrids were produced in the crosses of ' $\mathrm{RA}-89$ ' $\times$ rape and rape $\times$ ' $\mathrm{Rb}$ 63 ', respectively. In the cross of 'RA-89' $\times$ rape, the somatic chromosomes of $21 \mathrm{~F}_{1}$ hybrids were $2 \mathrm{n}=38$, and their genome constitutions were assumed to be "RAAC". On the other hand, $11 \mathrm{~F}_{1}$ hybrids obtained in the crosses of rape $\times$ 
Table 1. Distribution of somatic chromosome numbers in $\mathrm{BC}_{1}, \mathrm{BC}_{2}$ and $\mathrm{BC}_{3}$ plants derived from both alloplasmic $\mathrm{F}_{1}$ plant (Raphanobrassica 'RA-89' $\times$ rape, $2 \mathrm{n}=76$ ) and autoplasmic $\mathrm{F}_{1}$ plant (rape $\times$ Raphanobrassica ' $\mathrm{Rb}-63$ ', $2 \mathrm{n}=74$ ) after successive backcrosses to $B$. napus strain ' $\mathrm{N}-350$ '

\begin{tabular}{|c|c|c|c|c|c|c|c|c|c|c|c|c|c|c|c|c|c|c|c|c|c|c|c|}
\hline \multirow{2}{*}{ Line } & \multirow{2}{*}{$\begin{array}{c}\text { No. of plants } \\
\text { Observed }\end{array}$} & \multicolumn{22}{|c|}{ Somatic chromosome number $(2 n)$} \\
\hline & & $<38$ & 38 & 39 & 40 & 41 & 42 & 43 & 44 & 45 & 46 & 47 & 48 & 49 & 50 & 51 & 52 & 53 & 54 & 55 & - & 57 & $57<$ \\
\hline \multicolumn{24}{|c|}{$<$ <alloplasmic $>$} \\
\hline \multirow[t]{2}{*}{$\mathrm{BC}_{1}$} & $95^{a}$ & 1 & 1 & & 1 & & 2 & 3 & 6 & 5 & 5 & 9 & 6 & 4 & 10 & 14 & 13 & 6 & 2 & 1 & & 1 & 5 \\
\hline & $(\%)$ & 1.1 & 1.1 & & 1.1 & & 2.1 & 3.2 & 6.3 & 5.3 & 5.3 & 9.5 & 6.3 & 4.2 & 10.5 & 14.7 & 13.7 & 6.3 & 2.1 & 1.1 & & 1.1 & 5.3 \\
\hline \multirow{2}{*}{$\mathrm{BC}_{2}^{b}$} & 83 & 7 & 10 & 17 & 14 & 13 & 9 & 8 & 4 & & & & 1 & & & & & & & & & & \\
\hline & $(\%)$ & 8.4 & 12.0 & 20.5 & 16.9 & 15.7 & 10.8 & 9.6 & 4.8 & & & & 1.2 & & & & & & & & & & \\
\hline \multirow[t]{2}{*}{$\mathrm{BC}_{3}{ }^{c}$} & 190 & 22 & 59 & 50 & 28 & 19 & 7 & 1 & 2 & & & & & & 1 & & & & & & & & 1 \\
\hline & $(\%)$ & 11.6 & 31.1 & 26.3 & 14.7 & 10.0 & 3.7 & 0.5 & 1.1 & & & & & & 0.5 & & & & & & & & 0.5 \\
\hline \multicolumn{24}{|c|}{$<$ autoplasmic $>$} \\
\hline \multirow[t]{2}{*}{$\mathrm{BC}_{1}$} & 25 & & & & & & & & & 2 & & 6 & 3 & 1 & & 4 & 2 & 1 & 2 & & & 3 & 1 \\
\hline & $(\%)$ & & & & & & & & & 8.0 & & 24.0 & 12.0 & 4.0 & & 16.0 & 8.0 & 4.0 & 8.0 & & & 12.0 & 4.0 \\
\hline \multirow[t]{2}{*}{$\mathrm{BC}_{2}{ }^{d}$} & 62 & & 1 & 2 & 7 & 7 & 14 & 18 & 5 & 5 & 2 & 1 & & & & & & & & & & & \\
\hline & $(\%)$ & & 1.6 & 3.2 & 11.3 & 11.3 & 22.6 & 29.0 & 8.1 & 8.1 & 3.2 & 1.6 & & & & & & & & & & & \\
\hline \multirow[t]{2}{*}{$\mathrm{BC}_{3}{ }^{e}$} & 181 & & 50 & 69 & 43 & 16 & 3 & & & & & & & & & & & & & & & & \\
\hline & $(\%)$ & & 27.6 & 38.1 & 23.8 & 8.8 & 1.7 & & & & & & & & & & & & & & & & \\
\hline
\end{tabular}

${ }^{a}$ In total $95 \mathrm{BC}_{1}$ plants, 78 were obtained by backcross with $B$. napus strain ' $\mathrm{N}-350$ ' following to embryo culture.

${ }^{b} \mathrm{BC}_{2}$ plants were obtained from $2 \mathrm{BC}_{1}$ plants with $2 \mathrm{n}=47$ and 52 by backcrossing to B. napus strain ' $\mathrm{N}-350$ '.

${ }^{c} \mathrm{BC}_{3}$ plants were obtained from $5 \mathrm{BC}_{2}$ plants with $2 \mathrm{n}=39$ to 43 by backcrossing to B. napus strain ' $\mathrm{N}-350$ '.

${ }^{d} \mathrm{BC}_{2}$ plants were obtained from $3 \mathrm{BC}_{1}$ plants with $2 \mathrm{n}=47$ and 48 by backcrossing to $B$. napus strain ' $\mathrm{N}-350$ '.

${ }^{e} \mathrm{BC}_{3}$ plants were obtained from $5 \mathrm{BC}_{2}$ plants with $2 \mathrm{n}=40$ to 42 by backcrossing to B. napus strain ' $\mathrm{N}-350$ '.

'Rb-63' were $2 \mathrm{n}=37$, with assumed genome of "ACRC". These $\mathrm{F}_{1}$ hybrids obtained in each cross-combination exhibited morphological characteristics that are intermediate between their parents. The $F_{1}$ hybrids produced abortive pollens and no seeds were obtained by the crossing with rape. Each allooctoploid line obtained from two crosscombinations by colchicine treatment was repeatedly backcrossed to rape, producing $\mathrm{BC}_{1}, \mathrm{BC}_{2}$ and $\mathrm{BC}_{3}$ plants. Somatic chromosome numbers of these progenies were shown in Table 1. In alloplasmic line, the seed setting of $2 \mathrm{BC}_{1}$ plants $\left(2 \mathrm{n}=47\right.$ and 52) which were used to produce $\mathrm{BC}_{2}$ plants was 6.9 and 3.4 seeds, respectively, after backcrossing with rape. From the morphological and cytogenetical observations, these materials were assumed to be the AACC genome constitution added $1 \mathrm{R}$-genome with some alien chromosomes. In $\mathrm{BC}_{3}$ generation, the $2 \mathrm{n}=39$ plants were progressively obtained. The number of plants obtained were $50(26.3 \%)$ in alloplasmic lines and 69 (38.1\%) in autoplasmic lines, although they were first obtained in $\mathrm{BC}_{2}$ generation.

In the profiles of GISH, 9 signals were observed in somatic chromosome of radish, whereas no signal was detected in rape (date not shown). Eighteen radish signals were observed in somatic metaphase chromosome of Raphanobrassica (Fig. 2A), and a single large radish signal was observed in the $2 n=39$ plant (Fig. 2B). This result confirmed that the radish chromosome derived from Raphanobrassica was substantially transferred to the backcross progenies. On the other hands, a lot of small signals were also detected in the somatic cell of $2 n=39$ plant. These small signals may reflect the homoeologous regions to $\mathrm{R}$ genome included in $\mathrm{A}$ - and $\mathrm{C}$-genomes of rape.

After examining a total of 400 RAPD primers for prelim-

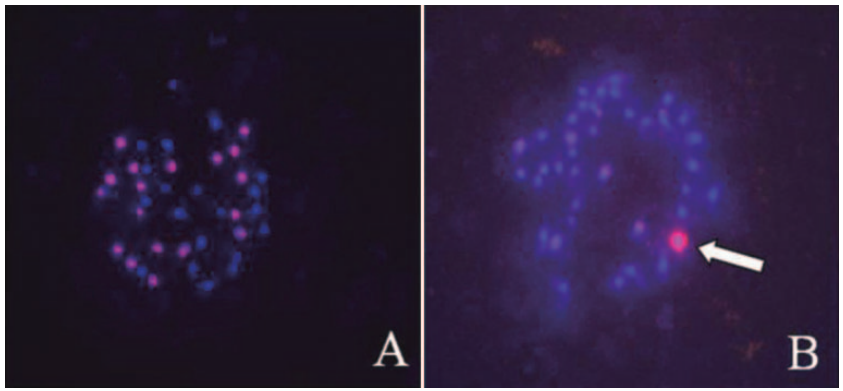

Fig. 2. Genomic in situ hybridization of radish total DNA (red) probes to somatic metaphase chromosomes of Raphanobrassica (A) and the $2 \mathrm{n}=39$ plant (B). The chromosomes are counter-stained with DAPI (blue). Arrow indicates radish chromosome.

inary classification of MALs, 232 markers specific to Rgenome were detected from 99 primers. Of these 175 markers could be classified tentatively into 8 types ( $\mathrm{a}-\mathrm{i}$, except for the h-type) according to their segregation patterns (Table 2). The number of types for R-genome specific markers in the $14 \mathrm{BC}_{2}$ plants was close agreement with the number of added radish chromosomes expected from somatic chromosome number of these plants. Therefore, these 8 types may correspond to each of 8 chromosomes of the R-genome, and these markers specific to each type may be useful for the identification of radish chromosomes in further crosses with rape.

On the other hands, 8 types similar to alloplasmic line were detected in the $10 \mathrm{BC}_{2}$ plants of autoplasmic line, and $10 \mathrm{R}$-genome specific markers that had not detected in alloplasmic line were newly detected in $2 \mathrm{BC}_{2}$ plants (No. 1 and 10) (Table 3). These 10 markers were assumed to correspond 
Table 2. Identification of the added radish chromosomes by RAPD specific markers in $\mathrm{BC}_{2}$ plants $(2 \mathrm{n}=39 \sim 43)$ of alloplasmic (radish cytoplasm) line

\begin{tabular}{|c|c|c|c|c|c|c|c|c|c|c|c|c|c|c|c|c|}
\hline \multirow{2}{*}{ Type } & \multicolumn{14}{|c|}{ "Sample No. } & \multirow{2}{*}{ Total } & \multirow{2}{*}{$\begin{array}{l}\text { Specific } \\
\text { markers }\end{array}$} \\
\hline & 1 & 2 & 3 & 4 & 5 & 6 & 7 & 8 & 9 & 10 & 11 & 12 & 13 & 14 & & \\
\hline $\mathrm{a}$ & + & + & & + & & & & & + & + & & & & & 5 & 42 \\
\hline $\mathrm{b}$ & & & & & & & & & & + & & & & & 1 & 19 \\
\hline $\mathrm{c}$ & + & & & & & & & & & + & & & & & 2 & 19 \\
\hline d & & + & + & + & & & & + & + & & & + & & + & 7 & 28 \\
\hline $\mathrm{e}$ & & & & + & + & & & & + & & & & & + & 4 & 25 \\
\hline $\mathrm{f}$ & + & & & & & & & & & & & & & & 1 & 16 \\
\hline $\mathrm{g}$ & & + & & & & & & & & & & & + & + & 3 & 11 \\
\hline $\mathrm{h}$ & & & & & & & & & & & & & & & - & - \\
\hline i & + & + & + & & + & + & + & & + & + & + & & + & + & 11 & 15 \\
\hline Total & 4 & 4 & 2 & 3 & 2 & 1 & 1 & 1 & 4 & 4 & 1 & 1 & 2 & 4 & & 175 \\
\hline $\mathrm{Ex}^{a}$ & 3 & 2 & 1 & 1 & 2 & 2 & 1 & 1 & 3 & 5 & 1 & 1 & 2 & 2 & & \\
\hline $2 \mathrm{n}^{b}$ & 41 & 40 & 39 & 39 & 40 & 40 & 39 & 39 & 41 & 43 & 39 & 39 & 40 & 40 & & \\
\hline
\end{tabular}

${ }^{a}$ Number of radish chromosomes expected from somatic chromosome number.

${ }^{b}$ Somatic chromosome number.

Table 3. Identification of the added radish chromosomes by RAPD specific markers in $\mathrm{BC}_{2}$ plants $(2 \mathrm{n}=39 \sim 41)$ of autoplasmic (rape cytoplasm) line

\begin{tabular}{|c|c|c|c|c|c|c|c|c|c|c|c|c|c|}
\hline \multirow{2}{*}{ Type } & \multicolumn{10}{|c|}{ Sample No. } & \multirow{2}{*}{ Total } & \multirow{2}{*}{\multicolumn{2}{|c|}{ List of specific markers }} \\
\hline & 1 & 2 & 3 & 4 & 5 & 6 & 7 & 8 & 9 & 10 & & & \\
\hline $\mathrm{a}$ & & & & + & & & & & & & 1 & $10^{a}$ & $\begin{array}{l}\mathrm{A} 12_{510}, \mathrm{~A} 48_{360}, \mathrm{~B} 01_{290}, \mathrm{~B} 04_{620}, \mathrm{~B} 15_{620}, \mathrm{~B} 35_{670}, \\
\mathrm{~B} 35_{520}, \mathrm{C} 40_{820}, \mathrm{C} 40_{340}, \mathrm{D} 60_{200}\end{array}$ \\
\hline $\mathrm{b}$ & + & & + & & & & + & & & & 3 & 5 & $\mathrm{~A} 09_{420}, \mathrm{~A} 09_{190}, \mathrm{~A} 12_{620}, \mathrm{D} 25_{190}, \mathrm{D} 76_{220}$ \\
\hline $\mathrm{c}$ & & & & + & & + & & + & & & 3 & 4 & $\mathrm{~A} 26_{820}, \mathrm{~A} 94_{620}, \mathrm{~B} 42_{510}, \mathrm{~B} 88_{200}$ \\
\hline $\mathrm{d}$ & & & & & & & & + & + & & 2 & 6 & $\mathrm{~A} 26_{470}, \mathrm{~A} 57_{620}, \mathrm{~B} 15_{470}, \mathrm{~B} 35_{770}, \mathrm{~B} 42_{300}, \mathrm{~B} 96_{2040}$ \\
\hline $\mathrm{e}$ & & + & & + & + & + & + & & & + & 6 & 4 & $\mathrm{~A} 98_{520}, \mathrm{~B} 88_{440}, \mathrm{D} 72_{300}, \mathrm{D} 94_{200}$ \\
\hline $\mathrm{f}$ & & & & & & + & + & & & + & 3 & 4 & $\mathrm{~A} 13_{280}, \mathrm{~A} 66_{470}, \mathrm{C} 30_{470}, \mathrm{C} 79_{470}$ \\
\hline g & & & & + & + & & & + & & & 3 & 4 & $\mathrm{~A} 39_{770}, \mathrm{~A} 39_{620}, \mathrm{~A} 83_{820}, \mathrm{D} 07_{470}$ \\
\hline $\mathrm{h}$ & + & & & & & & & & & + & 2 & 10 & $\begin{array}{l}\mathrm{A} 14_{300}, \mathrm{~A} 14_{170}, \mathrm{~A} 35_{520}, \mathrm{~A} 37_{280}, \mathrm{~A} 39_{520}, \mathrm{~A} 39_{300}, \\
\mathrm{~B} 01_{440}, \mathrm{~B} 01_{340}, \mathrm{~B} 32_{340}, \mathrm{C} 30_{420}\end{array}$ \\
\hline $\mathrm{i}$ & & & + & & + & & & & & + & 3 & 4 & $\mathrm{~B} 8_{510}, \mathrm{~B} 15_{320}, \mathrm{~B} 55_{320}, \mathrm{C} 30_{320}$ \\
\hline Total & 2 & 1 & 2 & 4 & 3 & 3 & 3 & 3 & 1 & 4 & - & 51 & \\
\hline $\mathrm{Ex}^{b}$ & 2 & 1 & 3 & 2 & 2 & 3 & 3 & 2 & 1 & 2 & & & \\
\hline $2 \mathrm{n}^{c}$ & 40 & 39 & 41 & 40 & 40 & 41 & 41 & 40 & 39 & 40 & & & \\
\hline
\end{tabular}

${ }^{a}$ Number of used and detected specific markers.

${ }^{b}$ Number of radish chromosomes expected from somatic chromosome number.

${ }^{c}$ Somatic chromosome number.

to the remaining one chromosome of the R-genome and designated to 'h-type'.

Thus, from RAPD analysis, added radish chromosome composition in alloplasmic and autoplasmic $\mathrm{BC}_{2}$ progenies was established by each nine chromosome specific markers. By successive backcrosses for these $\mathrm{BC}_{2}$ progenies with rape and identification of radish chromosome using each chromosome specific RAPD markers, alloplasmic MAL with 8 types except for the h-type and autoplasmic MAL with complete 9 types were produced in $\mathrm{BC}_{3}$ and $\mathrm{BC}_{4}$ generations.

\section{Characteristics of the MALs}

Characteristics of alloplasmic and autoplasmic MALs were shown in Table 4. Germination rate varied among the types, ranging from "normal" (a-, c-, e-, f-, g-type) to "middle" (b-, h-, i-type) and "low" (d-type). The d-type showed a distinctly low germination rate in both alloplasmic and autoplasmic MALs. In alloplasmic MAL, most types had malformed flowers (antherless, petaloid, or stunted petals) (Fig. 3A-C), whereas all of the nine types in autoplasmic MAL produced normal flowers (Fig. 3D-F). The flowers of alloplasmic MAL were smaller than those of autoplasmic MAL. All the types of alloplasmic and autoplasmic MALs except for the g-type produced yellow flowers like rape. On the other hand, flowers of the g-type from both alloplasmic and autoplasmic MALs were characterized by their white color like radish. No morphological differences were recognized in their leaves among the MALs (date not shown).

All types of autoplasmic MAL predominantly exhibited 
Table 4. Morphological, physiological and cytogenetical characteristics of alloplasmic and autoplasmic MALs in $\mathrm{BC}_{3}$ to $\mathrm{BC}_{5}$ generations in the comparison with two radish cultivar 'Shogoin', 'Risou', two Raphanobrassica 'RA-89', 'Rb-63' and rape strain 'N-350'

\begin{tabular}{|c|c|c|c|c|c|c|c|c|c|c|c|c|c|c|c|c|c|c|c|c|c|c|}
\hline \multirow{3}{*}{ Character } & \multicolumn{17}{|c|}{ Nine types of two MALs } & \multirow{2}{*}{\multicolumn{2}{|c|}{ Radish }} & \multirow{2}{*}{\multicolumn{2}{|c|}{ Raphanobrassica }} & \multirow{3}{*}{$\frac{\text { Rape }}{\mathrm{N}-350}$} \\
\hline & \multicolumn{2}{|r|}{ a } & \multicolumn{2}{|r|}{$\mathrm{b}$} & \multicolumn{2}{|r|}{$\mathrm{c}$} & \multicolumn{2}{|r|}{$\mathrm{d}$} & \multicolumn{2}{|r|}{$\mathrm{e}$} & \multicolumn{2}{|r|}{$\mathrm{f}$} & \multicolumn{2}{|r|}{$\mathrm{g}$} & \multirow{2}{*}{$\begin{array}{c}\mathrm{h} \\
\text { auto }\end{array}$} & \multicolumn{2}{|r|}{$\mathrm{i}$} & & & & & \\
\hline & allo $^{a}$ & auto $^{b}$ & allo & auto & allo & auto & allo & auto & allo & auto & allo & auto & allo & auto & & allo & auto & Risou $\mathrm{S}$ & Shogoin & RA-89 & $\mathrm{Rb}-63$ & \\
\hline No. of plants observed & d 12 & 1 & 11 & 11 & 5 & 4 & 4 & 1 & 8 & 7 & 1 & 2 & 2 & 2 & 10 & 6 & 6 & 5 & 5 & 5 & 5 & 5 \\
\hline Germination rate $(\%)$ & 98.0 & 94.0 & 62.0 & 98.0 & 92.0 & 92.0 & 44.0 & 61.4 & 96.0 & 100.0 & 96.0 & 100.0 & 96.0 & 96.0 & 88.0 & 72.0 & 78.0 & 100.0 & 100.0 & 70.0 & 50.0 & 100.0 \\
\hline Flower & & & & & & & & & & & & & & & & & & & & & & \\
\hline malformation & $--^{c}$ & - & $+^{d}$ & - & + & - & + & - & + & - & + & - & + & - & - & + & - & - & - & - & - & - \\
\hline Petal length (mm) & 15.5 & 14.7 & 13.3 & 15.7 & 16.0 & 17.9 & 12.9 & 16.1 & 15.3 & 15.6 & 12.3 & 17.9 & 13.2 & 14.8 & 14.4 & 13.6 & 18.7 & 22.7 & 21.9 & 20.1 & 24.8 & 16.0 \\
\hline Petal color ${ }^{e}$ & $\mathrm{Y}$ & $\mathrm{Y}$ & $\mathrm{Y}$ & $\mathrm{Y}$ & $\mathrm{Y}$ & $\mathrm{Y}$ & $\mathrm{Y}$ & $\mathrm{Y}$ & $\mathrm{Y}$ & $\mathrm{Y}$ & $\mathrm{Y}$ & $\mathrm{Y}$ & W & $\mathrm{W}$ & $\mathrm{Y}$ & $\mathrm{Y}$ & $\mathrm{Y}$ & $\mathrm{W}$ & $\mathrm{W}$ & $\mathrm{W}$ & $\mathrm{W}$ & $\mathrm{Y}$ \\
\hline Pod length (mm) & 40.3 & 56.8 & 30.6 & 60.2 & 44.4 & 51.7 & 46.9 & 66.3 & 35.9 & 54.9 & 34.8 & 73.2 & 34.1 & 52.9 & 27.5 & 31.5 & 59.8 & 47.4 & 55.9 & 48.9 & 55.8 & 57.8 \\
\hline $\begin{array}{l}\text { Chromosome pairing } \\
\text { at MI of PMCs }\end{array}$ & $\mathrm{no}^{f} 1$ & $19_{\text {II }}+1_{I}$ & no & $19_{\text {II }}+1_{\text {I }}$ & no & $19_{\mathrm{II}}+1_{\mathrm{I}}$ & no & $19_{\text {II }}+1_{I}$ & no & $19_{\mathrm{II}}+1_{\mathrm{I}}$ & no & $19_{\mathrm{II}}+1_{\mathrm{I}}$ & no & $19_{\text {II }}+1_{\text {I }}$ & $19_{\text {II }}+1_{\mathrm{I}}$ & no & $19_{\text {II }}+1_{\mathrm{I}}$ & no & no & no & no & no \\
\hline Pollen tetrad (\%) & no & 97.3 & no & 92.3 & no & 98.0 & no & 96.5 & no & 94.6 & no & 99.2 & no & 98.6 & 97.1 & no & 100.0 & no & no & no & no & no \\
\hline Pollen fertility (\%) & 88.0 & 87.9 & $\mathrm{~ms}^{g}$ & 82.9 & $\mathrm{~ms}$ & 83.0 & $\mathrm{~ms}$ & 87.2 & $\mathrm{~ms}$ & 47.6 & $\mathrm{~ms}$ & 88.1 & $\mathrm{~ms}$ & 89.5 & 79.5 & $\mathrm{~ms}$ & 84.9 & 93.4 & 94.8 & 62.6 & 85.9 & 95.9 \\
\hline Seed setting (grain) & 11.8 & 12.8 & 3.8 & 9.7 & 13.8 & 5.8 & 1.1 & 0.3 & 4.4 & 9.5 & 7.0 & 14.2 & 6.3 & 10.4 & 4.5 & 2.6 & 6.2 & 2.3 & 2.6 & 1.3 & 4.3 & 16.7 \\
\hline 1000 seed weight $(\mathrm{g})$ & 4.38 & 4.76 & 4.64 & 4.26 & 5.20 & 4.86 & 2.44 & 2.20 & 4.32 & 4.30 & 3.28 & 4.10 & 5.05 & 4.97 & 4.04 & 3.42 & 4.52 & 20.48 & 14.96 & 3.12 & 5.84 & 4.84 \\
\hline
\end{tabular}

${ }^{a}$ alloplasmic MAL carrying radish cytoplasm.

${ }^{b}$ autoplasmic MAL carrying rape cytoplasm.

${ }^{c}$ normal flowers with six normal anthers which producing abundant pollen.

${ }^{d}$ abnormal flowers such as antherless, petaloid and stunted petals.

${ }^{e} \mathrm{Y}$ : yellow, W: white.

${ }^{f}$ Not observed.

$g$ male sterility.

chromosome configuration of $19_{\mathrm{II}}+1_{\mathrm{I}}$ at $\mathrm{MI}$ of PMCs, and pollen tetrad ranged from $92.3 \%$ (b-type) to $100.0 \%$ (i-type). In autoplasmic MAL carrying the cytoplasm of rape, all of the nine types had a longer pod length than those of alloplasmic MAL although the h-type had a short pod $(28 \mathrm{~mm})$. In contrast, most of alloplasmic MAL having the radish cytoplasm showed short pod length and male sterility, and only the a-type produced normal flowers and had a high pollen fertility (88.0\%). Seed setting of the MALs in both alloplasmic and autoplasmic lines varied from 1.1 (d-type) to 13.8 (c-type) and from 0.3 (d-type) to 14.2 (f-type), respectively. The d-type from both lines showed a low seed setting and produced small seeds.

\section{Transmission rate of the added radish chromosome}

The calculated transmission rates in alloplasmic MALs varied from $11.6 \%$ for the g-type to $93.5 \%$ for the e-type, whereas those in autoplasmic MALs varied from $11.1 \%$ for the g-type to $100.0 \%$ for the d-type (Table 5). The d-type showed a high transmission rate in both MALs, whereas the g-type had a low transmission rate in both lines. These results might suggest that each radish chromosome added to the genetic background of rape was certainly transferred to the next generations via female gamete, although large differences were observed in the transmission rate of individual radish chromosomes.

\section{Discussion}

Dolstra (1982) has reported that productions of both $F_{1}$ hybrids and backcross progenies were difficult in direct hybridization between radish and rape due to their poor crossability. However, $\mathrm{F}_{1}$ hybrids were produced stably by using Raphanobrassica as the bridging plants in this study. This fact was also confirmed by Peterka et al. (2004). From these results, it was suggested that the amplidiploids such as Raphanobrassica or Brassicoraphanus are valuable to overcome the poor crossability between radish and rape. Khush and Brar (1992) reported that the crosses between the species with different ploidy levels are difficult to achieve, and the integration of ploidy levels in parent species may help overcome the hybridization barrier in these cross combinations. However, $\mathrm{F}_{1}$ plants (RAAC, $2 \mathrm{n}=38$; and ACRC, $2 \mathrm{n}=$ 37 ) showed extremely low pollen fertility and produced only a few progeny seeds even by open pollination (date not shown). So, the colchicine treatment was conducted for $F_{1}$ plants to improve both pollen and seed fertility by chromosome doubling. As a result, a large number of seeds were obtained from allooctaploid $\mathrm{F}_{1}$ plants (RRAAAACC and AACCRRCC) by backcrossing to $B$. napus to produce $\mathrm{BC}_{1}$ plants. The chromosome number of $\mathrm{BC}_{1}$ plants principally showed a tendency to be allopentaploid $(2 n=47 \pm \alpha)$ and was lower than the assumed chromosome number of $2 \mathrm{n}=57$ and 56 (RAAACC and AACCRC), and seed fertility of $\mathrm{BC}_{1}$ plants were improved. From these $\mathrm{BC}_{1}$ plants $(2 \mathrm{n}=47$ to 52$)$, the $\mathrm{BC}_{2}$ plants having the nuclear background of rape (AACC) with some alien chromosomes were obtained (Table 1). Moreover, in this study, we could bred both alloplasmic and autoplasmic MALs through only three or four time backcrosses with rape by application of Raphanobrassica (RRAA and RRCC) which is genetically-stable and maintained for a long term. Other MAL series were also effectively bred by using Raphanobrassica (Kaneko et al. 1987, 2001). Therefore, it is also suggested that the application of 
stable Raphanobrassica may effective for the reduction of breeding term of MAL.

For chromosome identification, nine types of R-genome specific RAPD markers corresponding to each of the nine chromosomes of radish were detected using the $\mathrm{BC}_{2}$ plants of both alloplasmic and autoplasmic lines and has been used in this study (Table 2 and Table 3 ). However, the number of types classified by each chromosome specific RAPD markers was occasionally inconsistent with the number of added radish chromosomes expected from somatic chromosome number in some plants of $\mathrm{BC}_{2}$ progenies. This discordance was observed also in the production of potato-tomato MALs (Garriga-Calderé et al. 1997) and rape-radish MALs (Peterka et al. 2004), and may be due to the chromosome substitution or translocation between a radish chromosome and $\mathrm{A}$ - or $\mathrm{C}$-genome chromosome of rape in this study. It was also suggested that the chromosomes of A- or C-genome of Raphanobrassica (RRAA or RRCC) were supplementally added with one of $\mathrm{R}$-genome in these $\mathrm{BC}_{2}$ progenies. By GISH analysis, it was clarified that the added chromosome for $2 \mathrm{n}=39$ plants is derived not from A- or C-genome but from R-genome of Raphanobrassica (Fig. 2B). Furthermore, in the cytogenetic observation for autoplasmic MAL, all of the nine types predominantly showed the chromosome configuration of $19 \mathrm{II}+1$ I (Table 4). The R. sativusB. oleracea MALs $(2 \mathrm{n}=19)$ and the $R$. sativus $-B$. rapa MALs $(2 \mathrm{n}=19)$ exhibited the chromosome configuration of $9 \mathrm{II}+1 \mathrm{I}$ at meiosis (Kaneko et al. 1987, 2001). These results were suggested that the chromosome of R-genome of radish was extremely rare syndesis with the chromosome of A- or C-genome in the genetic background of rape (AACC). Accordingly, the chromosomal configuration of $19 \mathrm{II}+1 \mathrm{I}$ in this study would result from complete synapsis to the homologous chromosomes of rape plus the added chromosome of the R-genome at meiosis. From these results of RAPD, GISH and cytogenetic analyses of MAL, it was confirmed that the 8-types of alloplasmic MAL and the complete 9-types of autoplasmic MAL were true MALs of alloplasmic (radish cytoplasm) and autoplasmic (rape cytoplasm) B. napus.

Investigation of morphological and physiological traits of alloplasmic and autoplasmic MALs and comparative studies of these MALs may be useful not only for analysis of gene(s) located on each chromosome, but also for analysis the interrelationship between cytoplasm and chromosomes of donor plant (Budahn et al. 2008). In alloplasmic line carrying the cytoplasm of radish, all of 8 types except for a-type produced the malformed flowers such as antherless or petaloid flowers and those with stunted petals (Fig. 3B, C and Table 4). Such phenomena have been observed in the progenies of intergeneric hybridization between $R$. sativus and B. napus (Paulmann and Röbbelen 1988). Attia and Röbbelen (1986) proposed that some of these disorders for fertility have been attributed to errors in the genetic control of meiotic chromosome configuration that is stabilized after repeated backcrosses to rape. Meanwhile, the disomic addition line

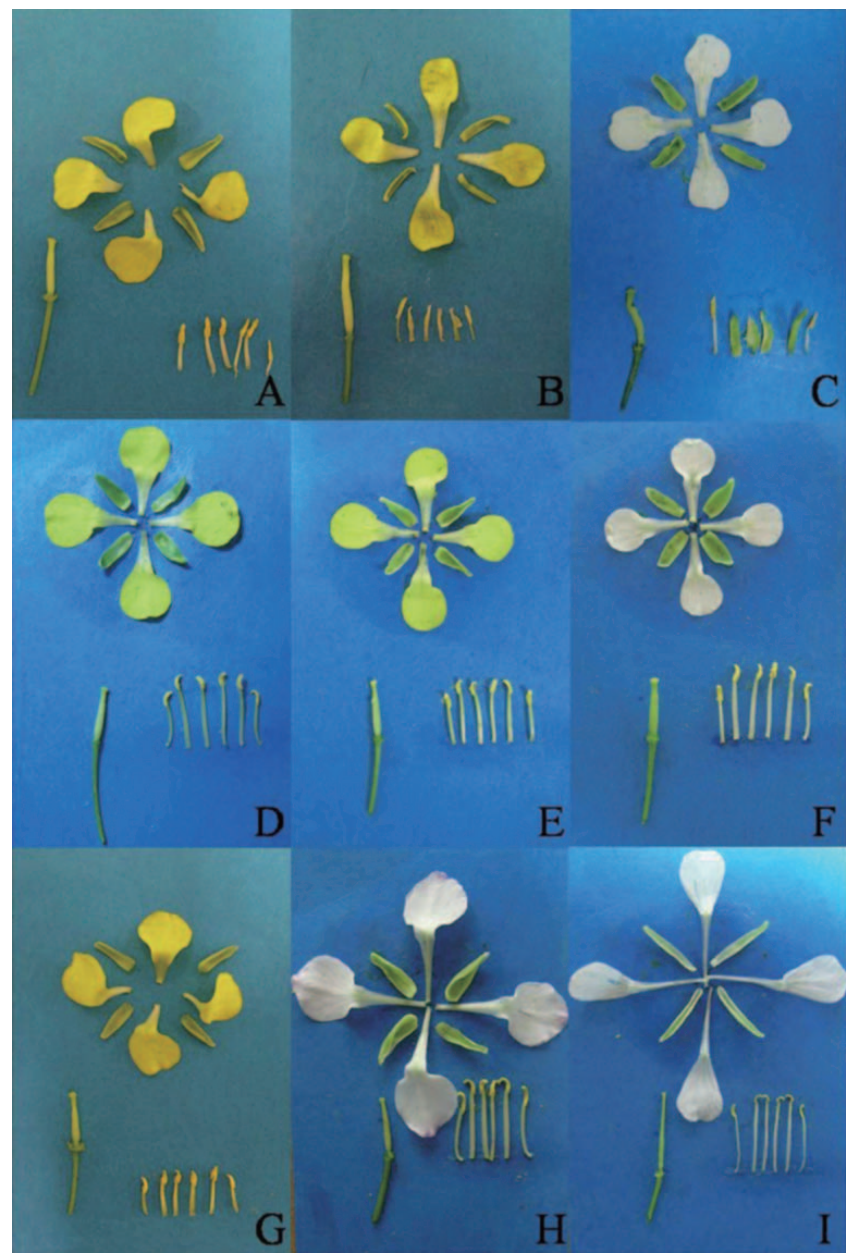

Fig. 3. Morphological features of flower in some types of alloplasmic and autoplasmic MALs; alloplasmic line $(\mathrm{A}-\mathrm{C})$ and autoplasmic line (D-F), and their parental species (G-I). Three types of MALs: a-type (A and D), d-type (B and E), and g-type (C and F). Parental species: B. napus strain 'N-350' $(\mathrm{G})$, Raphanobrassica ' $\mathrm{Rb}-63$ ' $(\mathrm{H})$, and R. sativus cv. 'Shogoin' (I).

(DAL) plants having a pair of radish chromosomes restored pollen fertility in the progenies of the somatic hybrids derived from protoplast fusion between $B$. napus and $R$. sativus with cytoplasmic male sterility (CMS) (Sakai and Imamura 2003). Bang et al. (2002) reported that some types (a, b, c, d, $\mathrm{e}, \mathrm{f}, \mathrm{k}$ and $\mathrm{l})$ in the $R$. sativus $-M$. arvensis MAL $(2 \mathrm{n}=19)$ restored male fertility, ranging from $3.4 \%$ to $85.6 \%$ in alloplasmic (Moricandia cytoplasm) radish. Budahn et al. (2008) also reported that only one type (designated as "ftype" in their terminology) in the alloplasmic (radish cytoplasm) B. napus - R. sativus MAL maintained male fertility. In this study, only the a-type in the alloplasmic (radish cytoplasm) MAL showed normal flowers and restored pollen fertility (88.0\%, Fig. 3A and Table 4) although all of the nine types in autoplasmic line produced normal flowers. Moreover, the meiotic chromosome configuration at MI in PMCs of autoplasmic MAL was $19 \mathrm{II}+1 \mathrm{I}$ and pollen tetrad (\%) showed high rate (Table 4 ), in contrast to what was observed 
Table 5. Female transmission rate of each radish chromosome in the alloplasmic and autoplasmic MALs (a- to i-type, $2 \mathrm{n}=39$ )

\begin{tabular}{lcccc}
\hline \hline Line & Type & Generations & $\begin{array}{c}\text { No. of plants } \\
\text { observed }\end{array}$ & $\begin{array}{c}\text { Transmission } \\
\text { rate of MAL (\%) }\end{array}$ \\
\hline$<$ alloplasmic $>$ & $\mathrm{a}$ & $\mathrm{BC}_{4}, \mathrm{BC}_{5}{ }^{a}$ & $32,42^{b}$ & $53.6 \pm 18.5$ \\
& $\mathrm{~b}$ & $\mathrm{BC}_{5}$ & 49 & 42.9 \\
& $\mathrm{c}$ & $\mathrm{BC}_{5}$ & 47 & 34.0 \\
& $\mathrm{~d}$ & $\mathrm{BC}_{4}$ & 36 & 72.2 \\
& $\mathrm{e}$ & $\mathrm{BC}_{4}, \mathrm{BC}_{5}$ & 37,47 & $93.5 \pm 0.2$ \\
& $\mathrm{f}$ & $\mathrm{BC}_{4}$ & 68 & 14.7 \\
& $\mathrm{~g}$ & $\mathrm{BC}_{4}, \mathrm{BC}_{5}$ & 67,152 & $11.6 \pm 11.7$ \\
& $\mathrm{i}$ & $\mathrm{BC}_{4}, \mathrm{BC}_{5}$ & 17,86 & $36.3 \pm 6.9$ \\
& $\mathrm{a}$ & $\mathrm{BC}_{4}$ & 40 & 50.0 \\
& $\mathrm{~b}$ & $\mathrm{BC}_{4}$ & 42 & 31.0 \\
& $\mathrm{c}$ & $\mathrm{BC}_{4}$ & 42 & 28.6 \\
& $\mathrm{~d}$ & $\mathrm{BC}_{3}$ & 21 & 100.0 \\
& $\mathrm{e}$ & $\mathrm{BC}_{4}$ & 45 & 60.0 \\
& $\mathrm{f}$ & $\mathrm{BC}_{3}$ & 49 & 30.6 \\
& $\mathrm{~g}$ & $\mathrm{BC}_{4}$ & 45 & 11.1 \\
& $\mathrm{~h}$ & $\mathrm{BC}_{4}$ & 42 & 33.3 \\
& $\mathrm{i}$ & $\mathrm{BC}_{4}$ & 46 & 28.3 \\
\hline
\end{tabular}

${ }^{a}$ the transmission rate was calculated in both $\mathrm{BC}_{4}$ and $\mathrm{BC}_{5}$ generations.

${ }^{b}$ the number of left and right are the number of plants observed in $\mathrm{BC}_{4}$ and $\mathrm{BC}_{5}$ generations, respectively.

by Paulmann and Röbbelen (1988). Therefore, it was suggested that the male sterility observed in this study was induced by the radish cytoplasm but not by the aberrancy in chromosome configuration at meiosis, and the fertility restoring gene(s) for male sterility may be located on the a-chromosome of radish. It was also assumed that the a-type in this study and the f-type in previous study by Budahn et al. (2008) would be having the same chromosome of radish. Therefore, comparative studies of these two strains of B. napus $-R$. sativus MAL may provide further information to understand the restore gene(s) for cytoplasmic male sterility in radish.

The g-types from both alloplasmic and autoplasmic lines were characterized by the distinctive white flowers similar to those of radish (Fig. 3C, F and Table 4). Kato and Tokumasu (1976) reported that a single dominant gene controlled white petal color in radish, and Sernyk and Stefansson (1982) reported that the B. napus strain added with a $R$. sativus chromosome developed at University of Manitoba produced white flowers. Therefore, it was assumed that a single dominant gene determining white petal color was located on the g-chromosome of radish. The g-type may trigger a study on the expression mechanism of white color pigmentation in Brassicaceae.

Germination rate, seed fertility and transmission rate are important factors for maintenance of MAL. In alloplasmic and autoplasmic lines, all of the types except for the d-type showed high germination rate and seed fertility (Table 4). Therefore, these MALs except for the d-type would be able to maintain their progenies by backcrossing with rape. On the other hands, the d-type of both alloplasmic and autoplasmic lines showed both low germination rate and extremely low seed fertility and produced small seeds. Some hybridization barriers inducing hybrid inviability, weakness and breakdown (Khush and Brar 1992) were assumed to exhibit these erosions by traits on the d-chromosome of radish. Moreover, the large differences in the transmission rate of individual radish chromosomes are consistent with similar reports for MALs from other Brassica species (Kaneko et al. 1987, 2001, Bang et al. 2002, Budahn et al. 2008). For the types with low transmission rate, selected smaller seeds (SSS) method may be effective for the acquisition of MALs and providing the valuable MAL plants for genetic research (Kaneko et al. 2003).

Several MAL series have been used to analyze for some agronomic traits and gene(s) located on the added chromosome, for example disease resistance to blackleg (Leptosphaeria maculans) (Chévre et al. 1996), turnip mosaic virus (TuMV) (Kaneko et al. 1996), beet cyst nematode (Peterka et al. 2004) and photorespiratory characteristics (Bang et al. 2009). The alloplasmic and autoplasmic MALs produced in this study are useful to explore agronomic traits locating on each chromosome of radish as well as to introgress the promising disease resistance gene(s) of radish to B. napus. Japanese radish cultivar 'Shogoin', which was used as the chromosome donor plant of autoplasmic MAL, shows complete clubroot resistance (Ashizawa et al. 1980). The evaluation of clubroot resistance of this MAL may be useful to examine the resistance mechanism of clubroot in radish.

Recently, Budahn et al. (2008) reported that they produced another B. napus $-R$. sativus MAL possessing radish chromosomes derived from fodder and/or oil radish. The MALs produced in this study are different from those of Budahn et al. (2008), since our MALs possess each of nine chromosomes derived from Japanese radish cultivars ('Risou' and 'Shogoin'). Our MALs, therefore, may provide more important information for the modification of freshradish cultivars in East Asia.

\section{Literature Cited}

Ashizawa,M., H. Yoshikawa and K.Hida (1980) Studies on the breeding of clubroot-resistance in cole crops. II. Screening of cole crops of clubroot-resistance (2), Bull. Vegetable and Ornamental Crops Res. Stn. A7: 35-75.

Attia,T. and G. Röbbelen (1986) Cytogenetic relationship within cultivated Brassica analyzed in amphihaploids from the three diploid ancestors. Can. J. Genet. Cytol. 28: 323-329.

Bang, S.W., Y.Kaneko and Y.Matsuzawa (1996) Production of intergeneric hybrids between Raphanus and Sinapis and the cytogenetics of their progenies. Breed. Sci. 46: 45-51.

Bang, S.W., Y.Kaneko, Y.Matsuzawa and K.S. Bang (2002) Breeding of Moricandia arvensis monosomic chromosome addition lines $(2 \mathrm{n}=19)$ of alloplasmic (M. arvensis) Raphanus sativus. Breed. Sci. 52: 193-199.

Bang, S.W., O.Ueno, Y.Wada, S.K.Hong, Y.Kaneko and Y.Matsuzawa (2009) Production and photorespiratory characteristics of 
Raphanus sativus $\left(\mathrm{C}_{3}\right)$-Moricandia arvensis $\left(\mathrm{C}_{3}-\mathrm{C}_{4}\right.$ intermediate $)$ monosomic and disomic addition lines in each parental cytoplasmic background. Plant Prod. Sci. (in press).

Budahn,H., O. Schrader and H.Peterka (2008) Development of a complete set of disomic rape-radish chromosome-addition lines. Euphytica 162: 117-128.

Chen, B.Y., V.Simonsen, C.Lannér-Herrer and W.K.Heneen (1992) A Brassica campestris-alboglabra addition line and its use for gene mapping, intergenomic gene transfer and generation of trisomics. Theor. Appl. Genet. 84: 592-599.

Chen, B.Y., R.B.Jørgensen, B.F.Cheng and W.K.Heneen (1997) Identification and chromosomal assignment of RAPD markers linked with a gene for seed color in a Brassica campestris-alboglabra addition line. Hereditas 126: 133-138.

Chévre, A.M., F. Eber, P. This, P. Barret, X. Tanguy, H. Brun, M.Delseny and M.Renard (1996) Characterization of Brassica nigra chromosomes and of blackleg resistance in $B$. napus $-B$. nigra addition lines. Plant Breed. 115: 113-118.

Chévre, A.M., F.Eber, P. Barret, P.Dupuy and J.Brace (1997) Identification of the different Brassica nigra chromosomes from both sets of $B$. oleracea-B. nigra and $B$. napus $-B$. nigra addition lines with a special emphasis on chromosome transmission and selfincompatibility. Theor. Appl. Genet. 94: 603-611.

Dolstra, O. (1982) Synthesis and fertility of $\times$ Brassicoraphanus and ways of transferring Raphanus characters to Brassica. Pudoc. Wageningen. I11. Agr. Res. Report. 917: 1-90.

Fukui, K. (1996) Plant chromosome at mitosis. In: Fukui, K. and S.Nakamura (eds.) Plant Chromosomes: laboratory methods. CRC Press, Boca Raton, pp. 1-18.

Garriga-Calderé, F., D.J. Huigen, F. Filotico, E. Jacobsen and M.S Ramanna (1997) Identification of alien chromosomes through GISH and RFLP analysis and the potential for establishing potato lines with monosomic additions of tomato chromosomes. Genome 40: 666-673.

Ikegaya, Y. (1986a) Practical cytoplasmic male sterile line 'UK-1' obtained from Chinese radish. Jpn. J. Breed. 36 (Suppl 1): 104-105.

Ikegaya, Y. (1986b) Frequent appearance of cytoplasmic male sterile plants in a radish cultivar 'Kosena'. Jpn. J. Breed. 36 (Suppl 2): 106-107.

Jahier,J., A.M.Chévre, A.M.Tanguy and F.Eber (1989) Extraction of disomic addition lines of Brassica napus-B. nigra. Genome 32: 408-413.

Kaneko,Y., Y.Matsuzawa and M.Sarashima (1987) Breeding of the chromosome addition lines of radish with single kale chromosome. Jpn. J. Breed. 37: 438-452.

Kaneko,Y., T.Natsuaki, S.W.Bang and Y.Matsuzawa (1996) Identification and evaluation of turnip mosaic virus (TuMV) resistance gene in kale monosomic addition lines of radish. Breed. Sci. 46 : $117-124$.

Kaneko,Y., H.Yano, S.W.Bang and Y.Matsuzawa (2001) Production and characterization of Raphanus sativus-Brassica rapa monosomic chromosome addition lines. Plant Breed. 120: 163-168.

Kaneko,Y., H.Yano, S.W.Bang and Y.Matsuzawa (2003) Genetic stability and maintenance of Raphanus sativus lines with an added Brassica rapa chromosome. Plant Breed. 122: 239-243.

Kaneko,Y., C.Kimizuka-Takagi, S.W.Bang and Y.Matsuzawa (2007) 3. Radish. In: Kole, C. (ed.) Genome Mapping and Molecular Breeding in Plants, Volume 5, Vegetables. Springer, Verlag Berlin Heidelberg, pp. 141-160.

Kato, M. and S. Tokumasu (1976) The mechanism of increased seed fertility accompanied with the change of flower color in
Brassicoraphanus. Euphytica 25: 761-767.

Khush, G.S. (1973) Cytogenetics of alien additions and substitutions. In: Cytogenetics of Aneuploids. Academic press, New York and London, pp. 238-258.

Khush, G.S and D.S.Brar (1992) Overcoming the barriers in hybridization. In: Kalloo, G. and J.B. Chowdhury (eds.) Distant Hybridization of Crop Plants. Springer, Verlag Berlin Heidelberg, pp. 47-61.

Kolte, S.J., D.K.Bordoloi and R.P.Awarthi (1991) The search for resistance to major diseases of rapeseed and mustard in India. GCIRC Rapeseed Congr. pp. 219-225.

Lelivelt, C.L.C. and F.A.Krens (1992) Transfer of resistance to the beet cyst nematode (Heterodera schachtii Schm.) into the Brassica napus $\mathrm{L}$. gene pool through intergeneric somatic hybridization with Raphanus sativus L. Theor. Appl. Genet. 83: 887-894.

Lelivelt, C.L.C., W.Lange and O.Dolstra (1993) Intergeneric crosses for the transfer of resistance to the beet cyst nematode from Raphanus sativus to Brassica napus. Euphytica 68: 111-120.

Luo, P., X.F.Li, Z.Q. Wang and Z.Q. Lang (1989) Studies on wide cross between rapeseed and oil radish. Proc of the Internat Congr of SABRAO, pp. 467-470.

Luo, P., Z.Q.Lan, J.Deng and Z.Q. Wang (2000) Application of in vitro organ culture in wide-cross breeding of rapeseed. Euphytica. 114: 217-221.

Matsuzawa, Y., Y.Kaneko and M.Sarashima (1985) Fertility in the intergeneric hybrid plant, Raphanobrassica. Bull. Coll. Agri. Utsunomiya Univ. 12: 31-39.

Matsuzawa,Y., T.Funayama, M.Kamibayashi, M.Konnai, S.W.Bang and Y.Kaneko (2000) Synthetic Brassica rapa-Raphanus sativus amphidiploid lines developed by reciprocal hybridization. Plant Breed. 119: 357-359.

Metz,P.L.J., J.P.Nap and W.J. Stiekema (1995) Hybridization of radish (Raphanus sativus L.) and oilseed rape (Brassica napus L.) through a flower-culture method. Euphytica 83: 159-168.

Ogura,H. (1968) Studies on the new male sterility in Japanese radish, with special reference on the utilization of this sterility towards the practical raising of hybrid seeds. Mem. Fac. Agric. Kagoshima Univ. 6: 39-78.

O' Mara, J.G. (1940) Cytogenetic studies on Triticale. I. A method for determining the effects of individual Secale chromosomes on Triticum. Genetics 25: 401-408.

Paulmann, W. and G. Röbbelen (1988) Effective transfer of cytoplasmic male sterility from radish (Raphanus sativus L.) to rape (Brassica napus L.). Plant Breed. 100: 299-309.

Pelletier, G., C.Primard, F. Vedel, P.Chetrit, R.Remy, P.Rousselle and M. Renard (1983) Intergeneric cytoplasmic hybridization in Cruciferae by protoplast fusion. Mol. Gen. Genet. 191: 244-250.

Peterka, H., H.Budahn, O.Schrader, R. Ahne and W. Schutze (2004) Transfer of resistance against the beet cyst nematode from radish (Raphanus sativus) to rape (Brassica napus) by monosomic chromosome addition. Theor. Appl. Genet. 109: 30-41.

Quiros,C.F., O.Ochoa, S.F.Kianian and D.Douches (1987) Analysis of the Brassica oleracea genome by the generation of B. campestrisoleracea chromosome addition lines: characterization by isozymes and rDNA genes. Theor. Appl. Genet. 74: 758-766.

Quiros, C.F., O. Ochoa and D.Douches (1988) Exploring the role of $\mathrm{x}=7$ species in Brassica evolution: hybridization with $B$. nigra and B. oleracea. J. Hered. 79: 351-358.

Sakai, T. and J. Imamura (1990) Intergeneric transfer of cytoplasmic male sterility between Raphanus sativus (cms line) and Brassica napus through cytoplast-protoplast fusion. Theor. Appl. Genet. 80: $421-427$ 
Sakai, T., H.J.Liu, M. Iwabuchi, J.Kohno-Murase and J. Imamura (1996) Introduction of a gene from fertility restored radish (Raphanus sativus) into Brassica napus by fusion of X-irradiated protoplasts from a radish restorer line and iodacetoamide-treated protoplasts from a cytoplasmic male-sterile cybrid of B. napus. Theor. Appl. Genet. 93: 373-379.

Sakai, T. and J. Imamura (2003) Development and utilization of hybrid-seed production system in rapeseeds (Brassica napus L.) Breed. Res. 5: 93-102.

Schwarzacher, T., A.R.Leitch and J.S.Heslop-Harrison (1994) DNADNA in situ hybridization-methods for light microscopy. In Harris, N. and K.J.Oparka (eds.) Plant Cell Biology—a Oractical Approach. Oxford University Press, Oxford, pp. 127-155.

Sernyk, J.L. and B.R.Stefansson (1982) White flower color in rape (Brassica napus) associated with a radish (Raphanus sativus) chromosome. Can. J. Genet. Cytol. 24: 729-734.

Snowdon, R., W.Luhs and W.Friedt (2007) 2. Oilseed Rape. In: Kole,
C. (ed.) Genome Mapping and Molecular Breeding in Plants, Volume 2, Oilseeds. Springer, Verlag Berlin Heidelberg, pp. 56-114.

Srinivasan, K., V.G. Malathi, P.B. Kirti, S. Prakash and V.L.Chopra (1998) Generation and characterisation of monosomic chromosome addition lines of Brassica campestris-B. oxyrrhina. Theor. Appl. Genet. 97: 976-981.

Struss, D., U. Bellin and G. Röbbelen (1991) Development of Bgenome chromosome addition lines of $B$. napus using different interspecific Brassica hybrids. Plant Breed. 106: 209-214.

Wang, Y.P., K. Sonntag, E. Rudloff, I. Groeneveld, J. Gramenz and C.C.Chu (2006) Production and characterization of somatic hybrids between Brassica napus and Raphanus sativus. Plant. Cell. Tiss. Organ. Cult. 86: 279-283.

Zhu, J.S., D. Struss and G.Röbbelen (1993) Studies on resistance to Phoma Lingam in Brassica napus-Brassica nigra addition lines. Plant Breed. 111: 192-197. 